\title{
South American Fruit Fly, Anastrepha fraterculus (Wiedemann) (Insecta: Diptera: Tephritidae) ${ }^{1}$
}

H. V. Weems, Jr. ${ }^{2}$

\section{Introduction}

Anastrepha fraterculus was described in the genus Dacus by Wiedemann (1830), based on specimens from Brazil. This species is of great economic importance because of the wide variety of plants which it attacks and its extensive distribution. In most of South America it probably is the most important species of Anastrepha. Despite its importance it has no accepted common name. It has been called the South American fruit fly, but this is an inappropriate name since the species, as currently understood, occurs also throughout most of Central America northward to southern Texas. There is increasing evidence that what has been considered for many years to be a species which varies widely throughout its range is a species complex which represents two or more species and possibly several biological rates, the Brazilian population being the true $A$. fraterculus described by Wiedemann.

Alan Stone (1942) believed A. fraterculus to be a highly variable species ranging from Texas to central South America, and he identified specimens from peach and guava as A. fraterculus. However, he further stated that populations occurring from Texas to Argentina eventually may be found to represent a complex of species rather than a single one. Baker (Baker et al. 1944) considered the Mexican form distinct from A. fraterculus, noting differences between Brazilian and Mexican forms. He observed that the Brazilian A. fraterculus possesses wing markings that differ from those of the Mexican form. The inverted $\mathrm{V}$ is separated from the main pattern, the wing thus resembling that of Anastrepha distincta Greene. The Mexican form has the inverted V connected with the main pattern, the wing thus resembling that of Anastrepha obliqua (MacQuart). However, occasional specimens occur in South America in which the inverted $\mathrm{V}$ is connected, and some specimens have been found in Mexico, usually males, in which the connection fades out. The ovipositors, too, differ slightly. Baker (1944) noted that those of the Mexican specimens vary very slightly from one host to another but that those from all hosts appear more tapered at the tip than do those of A. fraterculus from Brazil, and the opening seems slightly farther from the distal extremity.

1. This document is EENY-266 (originally published as DPI Entomology Circular 217), one of a series of Featured Creatures from the Entomology and Nematology Department, Florida Cooperative Extension Service, Institute of Food and Agricultural Sciences, University of Florida. Published: January 2002. This document is also available on Featured Creatures Website at http://creatures.ifas.ufl.edu. Please visit the EDIS Website at http://edis.ifas.ufl.edu. Additional information on these organisms, including many color photographs, is available at the Entomology and Nematology Department website at http://entnemdept.ifas.ufl.edu/.

2. H.V. Weems, Jr., Florida Department of Agriculture and Consumer Services, Division of Plant Industry, Gainesville, FL.

The Institute of Food and Agricultural Sciences (IFAS) is an Equal Employment Opportunity - Affirmative Action Employer authorized to provide research, educational information and other services only to individuals and institutions that function without regard to race, creed, color, religion, age, disability, sex, sexual orientation, marital status, national origin, political opinions or affiliations. For information on obtaining other extension publications, contact your county Cooperative Extension Service office. Florida Cooperative Extension Service / Institute of Food and Agricultural Sciences / University of Florida / Larry R. Arrington, Interim Dean 
In South America, A. fraterculus attacks various fruits including peach, Citrus, guava, Spondia, and Eugenia. The Mexican "A. fraterculus" has been reared from peach, guava, and rose apple. What appears to be the same thing or very similar, was reared from tropical almond, but only in the city of Veracruz. Tropical almond is not recorded as a host of A. fraterculus in South America. It may be that the Veracruz population associated with tropical almonds is more closely related to the typical A. obliqua of the West Indies. Larvae of the Veracruz population attacking tropical almond possess spiracular processes which resemble those of larvae of $A$. obliqua from Puerto Rico. Populations of Mexican "A. fraterculus" in northern Mexico occur commonly in the vicinity of Citrus, but no infestation in sour orange or other Citrus has been found in that region. Baker (Baker et al. 1944) noted that attempts to rear the Veracruz form which attacks tropical almond from Spondias were unsuccessful, although Spondias is one of the common hosts of A. fraterculus in South America. Dr. R.H. Foote (pers. comm.) recently stated that he believes there are at least 4 biologically distinct populations included in the A. fraterculus complex. There are several other species of Anastrepha which closely resemble the A. fraterculus complex, so that there is great difficulty in determining specific limits. Further biological and taxonomic studies, sampling populations throughout the range of this complex and in association with various fruit hosts, are needed to resolve these questions. Evidently all forms of this complex attack economically important plants.

\section{Synonyms}

This is a species complex that has not yet been studied in sufficient detail to permit a clear separation of the included species. Members of this species have also been known as:

Tephriitis mellea Walker

Trypeta unicolor Loew

Trypeta fraterculus (Wiedemann)

Dacus fraterculus Wiedemann
Anthomyia frutalis Weyenbergh

Anastrepha soluta Bezzi (as fraterculus var.)

Anastrepha peruviana Townsend

Anastrepha brasiliensis Greene

Anastrepha pseudofraterculus Capoor

Anastrepha costarukmanii Capoor

Anastrepha scholae Capoor

Acrotoxa fraterculus (Wiedemann)

(From White and Elson-Harris 1994)

\section{Distribution}

Range is continental America from the Rio Grande Valley of Texas to Argentina, Trinidad and Tobago. There are records from Chile, but it is not established (White and Elson-Harris 1994). This species has been trapped in abundance in Texas throughout the year, the peak of its occurrence being in January with a smaller one in August; It is least abundant there in March, April, and May (Stone 1942).

\section{Hosts}

The A. fraterculus complex has been reared from the following: Annona cherimola Mill. (cherimoya, chirimoya, custard apple, or cherimalla); Citrus maxima (Burm.) Merrill (=Citrus grandis (L.) Osbeck) (shaddock, pomelo, pumelo, pummelo, pommelo, or pompelmous); Citrus paradisi MacFady (grapefruit); Citrus reticulata Blanco (Mandarin orange, Satsuma orange, tangerine); Citrus sinensis (L.) Osbeck (sweet orange); Coffea arabica L. (common coffee or coffee); Cydonia oblonga Mill. (common quince); Dovyalis hebecarpa (G. Gardn.) Warb. (kitembilla or Ceylon gooseberry); Eriobotrya japonica (Thunb.) Lindl. (loquat, Japanese medlar, Japanese plum); Eugenia brasiliensis Lam. (=Eugenia dombeyi (Spreng.) Skeels) (Brazil cherry, grumichama, or grumixameira); Eugenia uniflora L. (Surinam cherry, Brazil cherry, Barbados cherry, Cayenne cherry, or pitanga); Mangifera indica $\mathrm{L}$. (mango); Manilkara (=Achras) zapota (L.) Van Royen (sapodilla, nispero, chicozapote, or 
naseberry); Prunus persica (L.) Batsch. (peach); Psidium guajava L. (common guava, yellow guava, or apple guava); Pyrus communis L. (pear or common pear); Spondias mombin L. (hog plum, yellow mombin, or jobo); Spondias nigrescens Pittier; Spondias purpurea L. (Spanish plum, red mombin, purple mombin, or jocote); Syzygium (=Eugenia) jambos (L.) Alston (rose apple or Malabar plum); Syzygium (=Eugenia) malaccense (L.) Merrill \& L.M. Perry (Malay apple, rose apple, large-fruited rose apple, or pomerac); Terminalia catappa L. (tropical almond, Indian almond, kamani, or myrobalan); Turpinia paniculata Vent.; Vitis vinifera L. (wine grape or European grape); and Ximenia americana L. (tallow-wood).

Of these food plants the Surinam cherry, peach, and guava seem to be particularly subject to attack. This species also has been reared experimentally from Annona glabra L. (pond apple), Malus pumila Mill. (common apple), and Phyllanthus acidus (L.) Skeels (Otaheite gooseberry or gooseberry tree).

\section{Identification}

\section{Eggs}

The eggs of A. fraterculus, typical of the genus, are creamy white, elongate, and tapering at the ends, averaging $1.4 \mathrm{~mm}$ in length and $0.2 \mathrm{~mm}$ in width at the midpoint. The micropylar end is twisted and is subapical rather than apical, characters distinguishing it from many other species of Anastrepha. There is a diamond-shaped sculpturing around the micropylar end, and there is a small tuft of pile at the extreme tip. Emmart (1933) gave a detailed comparison of the eggs of Mexican "A. fraterculus" with those of three other common species of Anastrepha. While location of eggs in fruit is difficult, when they can be obtained, an early identification of the species may be possible when working with several known species. A gravid female inserts her eggs into the fruit of a plant host with an eversible, sclerotized ovipositor.

\section{Larvae}

The developing larvae molt three times as they feed and grow. An inactive 4th-instar larval stage within the puparium precedes formation of a pupa. This process may occur within or on the host plant,
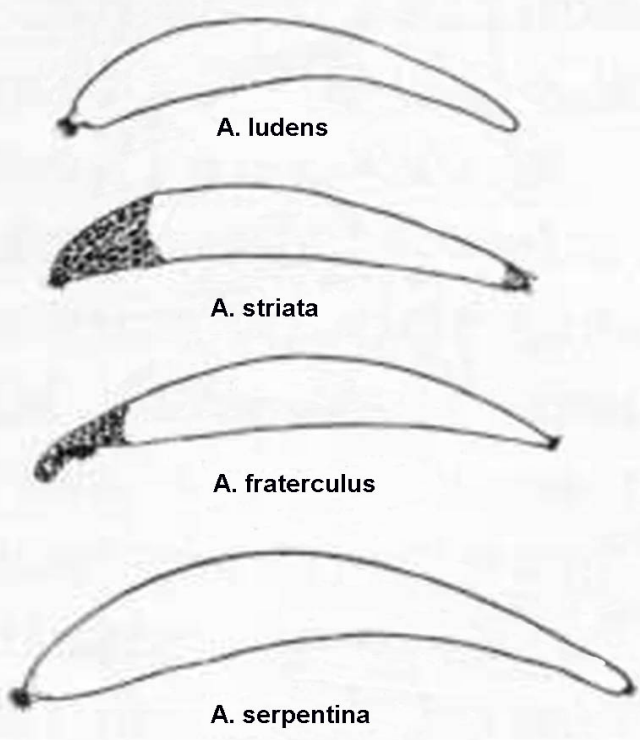

A. serpentina

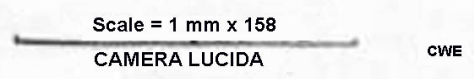

Figure 1. Egg of the South American fruit fly, Anastrepha fraterculus (Wiedemann), compared with other common Anastrepha species. Credits: Division of Plant Industry

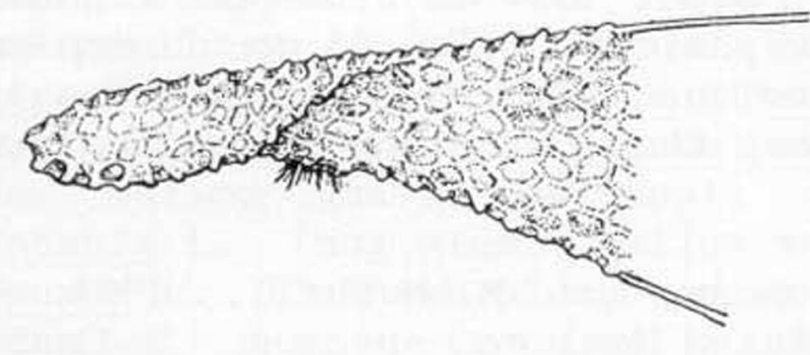

Figure 2. Micropyle and sculpturing on egg of the South American fruit fly, Anastrepha fraterculus (Wiedemann). Credits: Division of Plant Industry

but pupation occurs in the soil. The mature larva is 8 to $10 \mathrm{~mm}$ in length and $1.5 \mathrm{~mm}$ in diameter; pale yellowish white, tapering slightly toward the cephalic end; 11 segments of about equal length in addition to the head; a ventral fusiform area on anterior portion of each of segments 4 to 11 . Head small, partly retractile; mouth hooks medium-sized, 1st part rather slender, 1st and 2nd parts black, 3rd part with brown infuscation at base, and remainder of joint hyaline. Anterior spiracles small, yellowish, chitinized, with 15 to 17 small rounded tubules arranged in an 
irregular row. Posterior spiracles small, located well above medio-horizontal line.

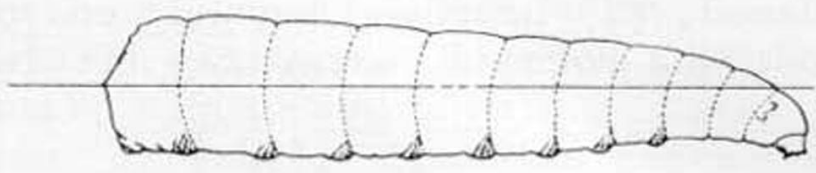

Figure 3. Lateral view of the larva of the South American fruit fly, Anastrepha fraterculus (Wiedemann). Credits: Division of Plant Industry

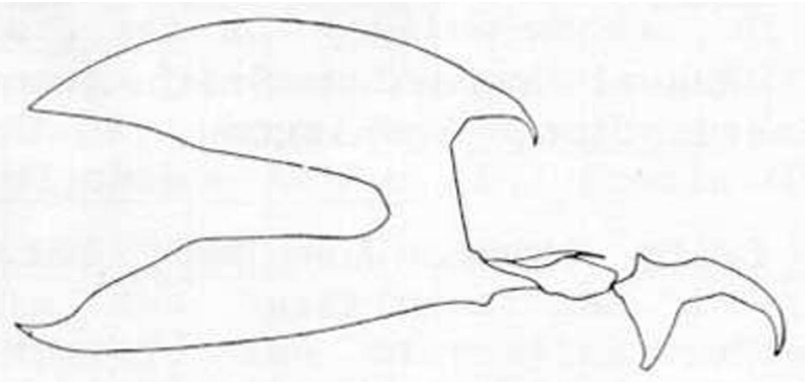

Figure 4. Larval mouth hook of the South American fruit fly, Anastrepha fraterculus (Wiedemann). Credits: Division of Plant Industry

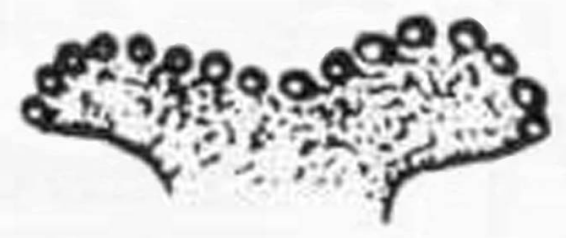

Figure 5. Anterior spiracle. Credits: Division of Plant Industry
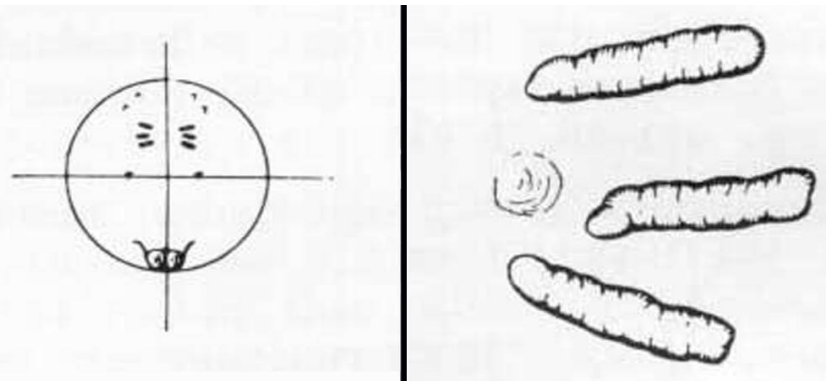

Figure 6. Posterior view of larva (left) and spiracle (right). Credits: Division of Plant Industry

\section{Pupae}

Pupae 4.5 to $6.0 \mathrm{~mm}$ long, 2 to $2.5 \mathrm{~mm}$ in diameter; cylindrical, dull luteous to reddish yellow or dark red; 11 distinct segments. Anterior spiracles like those of larva but much darker. Posterior spiracles medium sized, dark reddish, located in a faintly depressed hexagonal area which is on but mostly below the medio-horizontal line. Greene (1929) gave a detailed description of both larva and pupa, based on material collected in Panama.

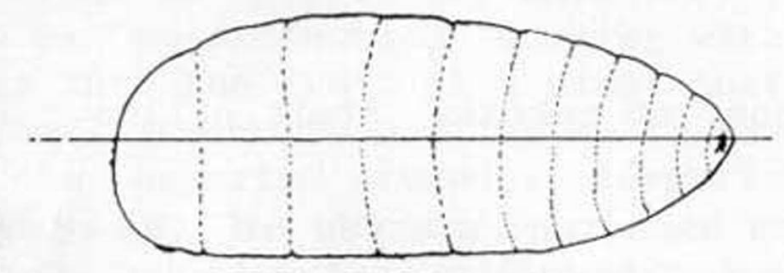

Figure 7. Lateral view of the pupa of the South American fruit fly, Anastrepha fraterculus (Wiedemann). Credits: Division of Plant Industry
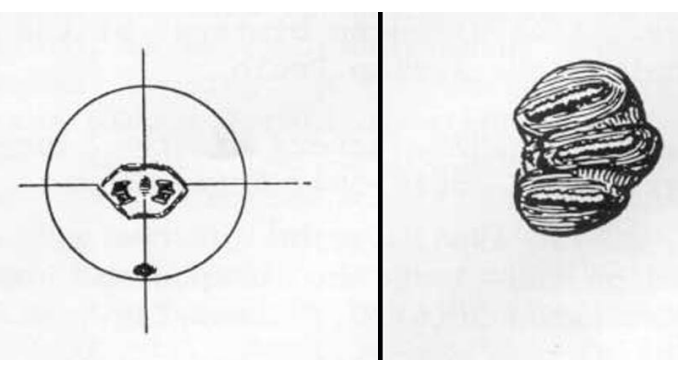

Figure 8. Posterior view of a pupa (left) and a posterior spiracle (right) of the South American fruit fly, Anastrepha fraterculus (Wiedemann). Credits: Division of Plant Industry

Fruit fly larvae and pupae are difficult to identify to species, and much more research is needed in this area.

\section{Adults}

Adult identification is based primarily on the female; male specimens in most cases are still indeterminable. It may be possible eventually to determine males, but much work must be done, even to associate sexes, before this can be accomplished. Steyskal (1977) presented a good pictorial key to species of Anastrepha. The following description of A. fraterculus is based primarily on Stone (1942): small to rather small, yellow brown. Mesonotum 2.75 to $3.3 \mathrm{~mm}$ long, yellow brown; the humerus, median stripe widened posteriorly anterior to acrostichal bristles and barely including these bristles, lateral 
stripe from transverse suture to scutellum, and scutellum bright yellow; a small diffuse scutoscutellar black spot may or may not be present; pleura yellow and yellow brown; metanotum and postscutellum rather broadly blackened laterally. Macrochaetae yellow brown to black; pile yellow brown.

Sternopleural bristle slender.

Wing 5.35 to $7.2 \mathrm{~mm}$ long, the bands yellow-orange and brown. As already stated, adult forms currently recognized within the A. fraterculus complex show substantial variation in the wing pattern. In the Brazilian form costal band typically touching $\mathrm{S}$ band and V band typically separated from $\mathrm{S}$ band.

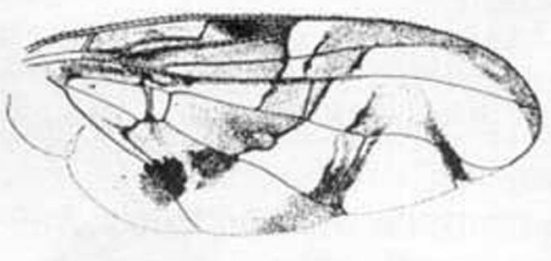

Figure 9. Right wing of an adult South American fruit fly, Anastrepha fraterculus (Wiedemann). Credits: Division of Plant Industry

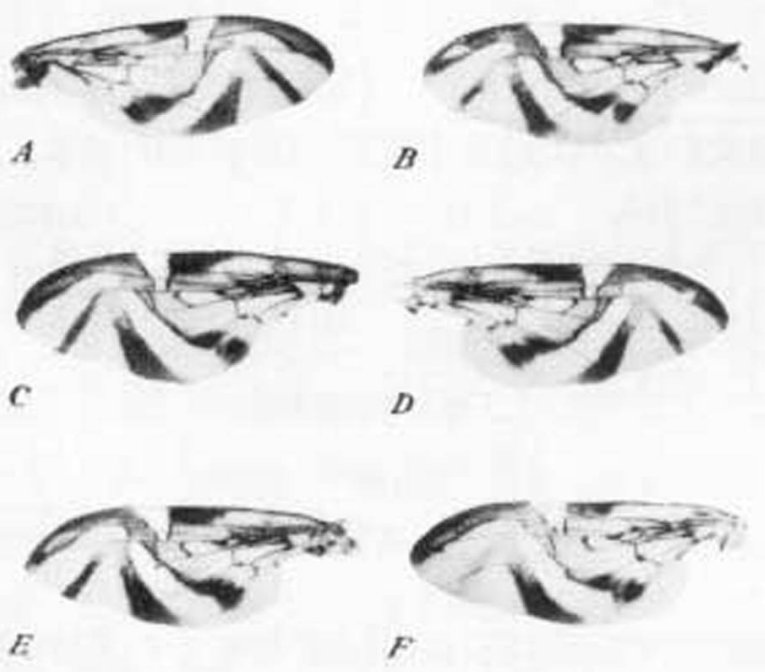

Figure 10. Various wing forms of the South American fruit fly, Anastrepha fraterculus (Wiedemann). a) typical form, Brazil, from sour orange; b) Mexican form from peach; c) Mexican form from guava; d) Mexican form from rose apple; e) Mexican form from tropical almond; f) Mexican form from rosa apple showing broken pattern. Credits: Division of Plant Industry
Ovipositor sheath 1.65 to $.1 \mathrm{~mm}$ long. stout, tapering apically, spiracles about $0.7 \mathrm{~mm}$ from base. Rasper a rather small patch of hooks in 4 or 5 rows. Ovipositor 1.5 to $1.95 \mathrm{~mm}$ long, stout, base distinctly widened, tip narrowed beyond end of oviduct and before serrate portion, the serrations blunt and rounded, extending little more than half length of tip, sometimes less.

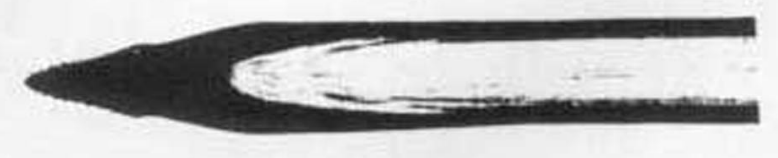

Figure 11. Ovipositor of typical form from Brazil. Credits: Division of Plant Industry

\section{Selected References}

Baker AC, Stone WE, Plummer CC, McPhail M. 1944. A review of studies on the Mexican fruitfly and related Mexican species. U.S. Department of Agriculture Miscellaneous Publication 531: 1- 155.

Baker EW. 1945. Studies on the Mexican fruitfly known as Anastrepha fraterculus. Journal of Economic Entomology 38 (1): 95-100.

Christenson LD. 1963. Tropical fruit-fly menace. Annual report Smithsonian Institution, 1962 (Publication 4557). Smithsonian Institution, Washington, D.C. p. 441-448.

Christenson LD, Foote RH. 1960. Biology of fruit flies. Annual Review of Entomology 5: 171-192.

Emmart EW. 1933. The eggs of four species of fruit flies of the genus Anastrepha. Proceedings of the Entomological Society of Washington 35: 184-191.

Foote H. 1967. No. 57, Family Tephritidae, p. 1-91. in: E.P. Vanzolini \& N. Papavero, eds., A catalogue of the Diptera of the Americas south of the United States. Dept. Zool. Secr. Agric., São Paulo.

Greene CT. 1929. Characters of the larvae and pupae of certain fruit flies. Journal of Agricultural Research 38: 489-504.

Greene CT. 1934. A revision of the genus Anastrepha based on a study of the wings and on the 
length of the ovipositor sheath (Diptera: Trypetidae).

Proceedings of the Entomological Society of

Washington 36: 127- 179.

Phillips VT. 1946. The biology and identification of trypetid larvae (Diptera: Trypetidae). Memoirs of the American Entomological Society 12: 1-161.

Seín F Jr. 1933. Anastrepha (Trypetydae, Diptera) fruit flies in Puerto Rico. Journal of the Department of Agriculture, Puerto Rico 17: 183-196.

Steyskal GC. 1977. Pictorial key to species of the genus Anastrepha (Diptera: Tephritidae). (Spec. Publ.) Entomological Society of Washington. Washington, D.C. 35 p.

Stone A. 1942. The fruitflies of the genus Anastrepha. U.S. Department of Agriculture Miscellaneous Publication 439: 1-112. Washington, D.C.

White IM, Elson-Harris MM. 1994. Fruit Flies of Economic Significance: Their Identification and Bionomics. CAB International. Oxon, UK. 601 p.

Wiedemann CRW. 1830. Aussereuropäische zweiflügelige Insekten. Vol. 2. 684 p.

Zucchi RA. 1979. Novas espècies de Anastrepha Schiner, 1868 (Diptera, Tephritidae). Rev. bras. Ent. 23: $35-41$. 